\title{
CROSS-CULTURAL COMMUNICATION AS A FACTOR OF MODERNIZATION OF EDUCATIONAL ACTIVITY
}

\author{
Zhainash Nurzhanova $^{1 *}$, Assel Kurmanbayeva ${ }^{2}$, Gaukhar Dauletbayeva ${ }^{3}$, Marfina \\ Maden $^{4}$, Sagdat Temirkhan ${ }^{5}$ \\ ${ }^{1}$ Associated Prof., L.N.Gumilyov Eurasian National University, Kazakhstan, znur73@mail.ru \\ ${ }^{2}$ Master student., L.N.Gumilyov Eurasian National University, Kazakhstan, asselya kb@mail.ru , \\ ${ }^{3}$ Master student., L.N.Gumilyov Eurasian National University, Kazakhstan, , gauhara nur@mail.ru , \\ ${ }^{4}$ Master student., L.N.Gumilyov Eurasian National University, Kazakhstan, znur73@mail.ru , \\ ${ }^{5}$ Master student., L.N.Gumilyov Eurasian National University, Kazakhstan, sagdat7-7@mail.ru
}

${ }^{*}$ Corresponding author

\begin{abstract}
This article is devoted to the theme of intercultural communication as a factor in the modernization of educational activities. The need for the formation of student's ability to intercultural communication studies led to the relevance of the process of mastering the laws of any age nonnative language in the language environment, as well as analysis of the factors that determine the success / failure of this process.

In recent years it has become apparent that the communication is a transmission from the addressee is not sent to the specific information. Communication flows more successfully than wider area of intersection of these spaces. Communicants important to have core knowledge and understanding, which is shared by all members of the linguaethnocultural community. Consequently, the student and the teacher should have a thorough understanding of the opportunities enjoyed by the study group, school, and region to create conditions for the formation of cross-cultural communication, both within the country and abroad.
\end{abstract}

Communication Through Culture provides: 1) the identity of the individual; 2) the interaction of the individual and society; 3) coordination of the activities of individuals among themselves; 4) the integration of social groups and social cohesion as a whole; 5) internal differentiation of society and the individual groups; 6) exchange of achievements between individuals, groups of individuals and nations.

Language can be seen as a tool for organizing meanings produced as a result of mental, emotional and mirosozertsatelnoy human activity, and as a means of transmission of meanings from one communicant to another. Contact natural language and culture is as follows: 1) the language contributes to the identification of the objects of the world (natural and man-made), their classification and ordering of information about him; 2) it helps to evaluate the objects, phenomena and their relationship; 3) facilitate human adaptation to environmental conditions; 4) promote the organization and coordination of human activity; 5) allows you to get psychological support for the correctness of their actions on other members of a linguistic community.

Thus, the language is an integral part of the spiritual culture of mankind together with other sign systems, 
which include the language of architecture, drama, music, dance, national symbols, rites, rituals, and others. Communication is a creative act of intuitive, which is based on an inherent and integral human need to communicate.

Formation of intercultural competence should be seen in connection with the development of the student's personality, his ability and willingness to participate in the dialogue of cultures on the basis of the principles of cooperation, mutual respect and tolerance for cultural differences and overcoming cultural barriers, particularly for modern foreign language teaching. That person Dialogism it is an important factor (ID) of and as a result makes it capable of participating in the dialogue of cultures.

Thus, the process of formation of the intercultural competence of the student's vocation to expand its overall outlook and overall competence. The development of the individual student, is in the comparison of at least two linguocultures, carried out on the basis of their own world view and understanding of the world and involves the perception and reflection of their own values and social relationships.

Keywords: intercultural communication, foreign language learning, communicative competence, social groups, the dialogue of cultures.

\section{INTRODUCTION}

Admittedly, the end of the XX century and the beginning of the XXI century is a period of global innovation in all fields of culture, economy, technology, social thought and personal life of each person. In the period of high technology and the Internet, the term "globalization" has firmly entered our dictionary. We are talking about the globalization of society, the globalization of economy and the globalization of education. It becomes obvious that in our century due to global changes in political and economic life learning a foreign language as a means of intercultural communication in a dialogue of cultures becomes an important issue.

A few years ago we used this phrase with caution in our speech, now it is possible to say that the dialogue of cultures has become a reality. The socio-cultural orientation, promoting the inclusion of pupils in the dialogue of cultures is one of the most important priorities in modern education. Practice shows that in modern conditions of constant expansion of the international contacts only being able to speak and write properly in a foreign language is not enough. A proper use of the norms of behavior, both verbal and non-verbal, is needed, which should be based on knowledge of the characteristics of the culture of the country of the target language.

The need to achieve understanding among peoples through dialogue of cultures dictates a search for new approaches to the problem of language and culture among ethno-psychological and didactic research. The study of the native language is to some extent a comprehension of the language picture of the world of its speakers. And the difficulty here may be caused by differences in the language picture of the world of native and studied languages. And not only objects or phenomena can be totally different in different cultures, but also it is important that there will be different cultural notions about these phenomena and objects, since the latter live and function in different, other worlds and cultures. Behind linguistic and cultural equivalence lies conceptual equivalence, cultural equivalence of representations.

\section{LITERATURE REVIEW}

\subsection{Intercultural communication}

Analyzing trends in the development of the theory and practice of teaching foreign languages the second half of the twentieth century, and D.Devidson, O.D.Mitrofanova write: "From 50th to 80th in the world have changed significantly methodological orientation, which is reflected in the leading terms of techniques, targeted training facilities, "language learning" changed to "the language of instruction as a means of communication," which has come to replace the "learning to communicate in a foreign language" or "learning foreign language training" ... (Davidson D., Mitrofanova O.D., 1990, p.3).

Since the mid-1980s intensively developed the idea of cultural integration in the theory and practice of teaching the subject. In the 1990s, in a methodical "everyday life" surely includes the concept of "intercultural competence" and "intercultural learning". It was in those years, communicative approach is entering a new stage of its development, related to the search for ways of interconnected communicative, socio-cultural and cognitive development of the student. This phase involves updating the last person on the basis of their 
knowledge of a stranger to him reality and perception of other cultures. Intercultural communication - one of the most important phenomena of modern society, which significantly affects the development of social relations within each country and between countries and peoples.

I.I.Haleeva notes that intercultural communication is seen as the process of communication (verbal and nonverbal) between communicators, which are carriers of different cultures and languages, anyway - a set of specific processes of interaction between people belonging to different cultures and languages. It is about cross-cultural communication can be carried out only when the communication partner does not only belong to different lingvoethnoculturals, but also aware of the fact of "foreignness" of each other (Khaleeva I.I., 1989, p.238).

According to T.N.Ushakova's opinion in psychology, it was found that the presence in the mind of each participant of communication of their personal baggage, for instance - their own culture (personal attitude to the surrounding world), and one way or another opposed him another world (other people's way of mind) creates a dialogic personality (Ushakova T.N., 1986, p.137).

In the context of cross-cultural interaction between participants consist intercultural relations in which "cultural consistency is known in moments of going beyond the boundaries of the system." This means that in terms of intercultural dialogue, the participants, using their lingvocultural experience and their national cultural traditions and habits, while trying to take into account also a language code, different customs and traditions, other norms of social behavior, realizing at the same time the fact of foreignness past. If this does not happen, then the act of intercultural communication can not take place or be broken due to the emergence of so-called "communication failures" that have more serious negative consequences for the understanding of the communication partners than language mistakes. The entire period of development of the communicative approach (until the mid-1980s) T.N.Ushakova proved that the ability to communicate on an intercultural level should be formed specifically and that if this is not done, communicants in advance "programmed" to misunderstanding conflict.

N.V.Baryshnikov believes that "individual national natural style" communication with the understanding lingvoethnocultural specifics of the target language media should characterize verbal and nonverbal behavior of students in cross-cultural communication with its foreign counterparts (Baryshnikov N.V.,2000), pp.5-13].

Classic E.Holl intercultural communication theory argues that culture itself is communication, and communication - culture (Hall E.,1959, p.169).

Communication Through Culture provides: 1) the identity of the individual; 2) the interaction of the individual and society; 3) coordination of the activities of individuals among themselves; 4) the integration of social groups and social cohesion as a whole; 5 ) internal differentiation of society and the individual groups; 6 ) exchange of achievements between individuals, groups of individuals and nations.

Language can be seen as a tool for organizing meanings produced as a result of mental, emotional and environmental human activity, and as a means of transmission of meanings from one communicator to another. Contact natural language and culture is as follows: 1) the language contributes to the identification of the objects of the world (natural and man-made), their classification and ordering of information about him; 2) it helps to evaluate the objects, phenomena and their relationship; 3) facilitate human adaptation to environmental conditions; 4) promote the organization and coordination of human activity; 5) allows you to get psychological support for the correctness of their actions on other members of a linguistic community.

Thus, the language is an integral part of the spiritual culture of mankind together with other sign systems, which include the language of architecture, drama, music, dance, national symbols, rites, rituals, and others. Communication is a creative act of intuitive, which is based on an inherent and integral human need to communicate.

\subsection{Communication through language is a dynamic mediation between the poles of knowledge}

Speaking about the relationship between the individual and the culture to which he belongs, F. Kluckhohn noted that no representative of the culture does not know all of its details. There is a certain part of the culture, which should be known to all of its carriers, some are selected on a competitive basis according to the needs of the communicator, and finally, the part that is used is limited and outlines the social role of the individual in a given society. That's why when intercultural communication important to be able to distinguish what is really worthy of attention as necessary for adequate communication, and the things without which you can do at communion.

As rightly pointed K.Freyk, culture is not so much a "cognitive map" as a set of guidelines for the creation of 
such a card, whose mission - to ensure the safety of swimming in a sea of foreign culture (Frake C.,1981, pp.138-150).

Based on the ideas of the Hall, GR Weaver likens the contact of two cultures meeting iceberg: it is "under water", at "non-obvious", there are basic clash of values and mentalities. He argues that the collision of the part of the cultural perception that was previously unconscious, reaches the level of the conscious and the person starts with a great understanding of how to treat her, and a foreign culture (Weaver G.R.,1993, pp.137-167).

In pedagogical literature in recent years, there are attempts to give a definition of dialogue given its ethnic content. In studies of such scientists as: N.Asipova., M.Dzhunusova., R.Dyusupova., M.Kuranov., M.S.Mikhailenko., I.Serov and others they widely considered such a thing as a "culture of interethnic communication." In teaching, there are works in which the essence of this concept is analyzed in relation to issues of international education (G.Burmistrov., A.Dmitriev., I.Maron and others). The culture of interethnic communication is understood in this context as a part of the spiritual life of society, its culture with all its laws, structure, functions and dynamics. Main socio - pedagogical importance of international dialogue, to convince by N.A.Asipova, it is that in the process of participation in it is an intensive formation of both international and national consciousness of the individual. The person dealing with the representatives of different ethnic groups, above all, knows himself as a person belonging to another nation (Kosherbaeva G.N.,2003, pp.80-84).

Kazakh scientist Z.K.Temirgazina believes that "an active current intercultural communication theory is focused on the study of the processes of communication between people, trapped in other cultures, unknown or unfamiliar environment, the conditions of effectiveness of such a foreign cultural communication." On the basis of this statement the term intercultural communication scholar defines (Temirgazina Z.K., 2003, pp.188-190). "dialogue of representatives of different ethnic and cultural groups within the different territorial and social space."

Scientist S.S.Dzhanseitova gives the following definition of intercultural communication: "Intercultural communication - the phenomenon of interaction between people from different ethnic and cultural groups (Dzhanseitova S.S., 2002, pp.165-170).

In the process of language learning students should familiarize themselves with the key concepts, which are necessary for an understanding of cross-cultural communication. Knowledge of concepts such as inculturation, acculturation, conflict of cultures, stereotypes contribute to the formation of intercultural communication and competence, which allows students to act as an intermediary between the representatives of their own and other cultures, to determine the causes of violations of intercultural communication and effectively eliminate misunderstandings and conflicts caused by ethnic and cultural differences .

Questions essence of formation of communicative competence and competence-based approach in the pedagogical process are considered in the works of Kazakhstan scientists, such as A.T.Chaklikova, L.V.Volkova, M.A.Absatova, Zh.Nurzhanova, G.K.Kulzhanbekova, N.A.Ozekbaeva, L.K.Karabaeva, V.S.Abaev, Sh.M.Maygeldieva, G.O.Rahimbekova, R.T.Kasymova, A.A.Chingisova, T.A.Kulguldinova, G.M.Badagulova, G.O.Orazbekova and others.

\section{CROSS-CULTURAL TRAINING}

\subsection{Intercultural competence}

Intercultural competence is treated in the study, developing an intercultural approach to teaching foreign languages, in different ways. Some scholars see it as the ability of people of different sex and age, peacefully and without mutual discrimination exist in the same society, others - like the ability to participate in someone else's before culture, and others - like identity, integrating knowledge and behavior patterns, which are based on the principles of pluralism of thought and awareness of the historicity of cultural processes. There is also a point of view that intercultural competence is a certain quality of a person based on a sober awareness of the world, history, and ready for action. Thus, on the background of the existing differences in the interpretation of the concepts of "intercultural competence" can be identified by scientists unanimously recognized its humanistic and educational values. 
Intercultural learning is well founded. It is caused by a number of objectively existing factors.

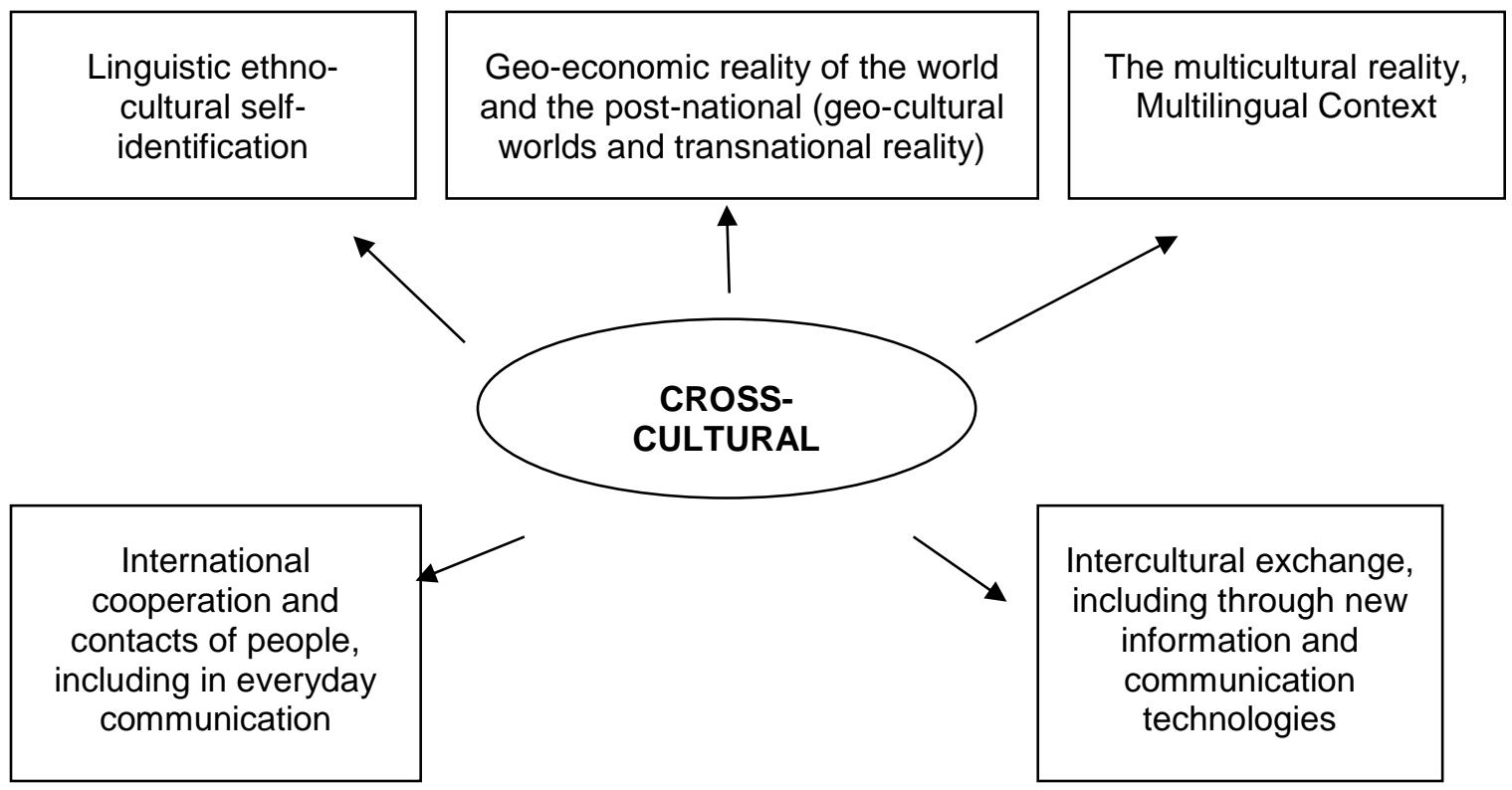

Fig. 1. Cross-Cultural Training

Under these conditions, it is especially important search diversity of languages and cultures of the mechanism of transformation of the factors hindering the dialogue between representatives of different lingual-social environment, a means of mutual understanding and enrichment tool in the creative development of socially active and independent person. Such a "mechanism" can be rightfully attributed language education, based on intercultural paradigm and proclaims as its guiding principle - the principle of multilingualism and multiculturalism, which provides social and academic mobility of youth.

In addition, in the coming new multi-dimensional and multicolor in terms of languages and cultures of the world the value of an old experience inferior values of creativity, values, personality development in a dynamically changing world. This fact underscores the importance of language learning, which is based on cross-cultural paradigm. Social and academic mobility of the person called upon to help her deeply feel that they belong to the native people and at the same time be aware of himself as a citizen of the country and the subject of Multicultural and Multilingual world civilization.

\subsection{The ways and forms of cross-cultural interaction}

Teaching a language as a means of intercultural communication has had a great significance in the modern society where we can observe broadening and strengthening of the economic and cultural links between people. Choosing secondary and high school students as a target group is motivated by psychological and personal peculiarities of this age that allow them to learn foreign languages effectively and develop communication skills.

According to modern educational concept in the area of language learning one of the basic goals of teaching a language is the development of students' abilities to use the language as the instrument of communication in the dialogue of cultures and civilizations of the modern world. This goal suggests correlated communicative and socio-cultural development of students by means of a foreign language for the preparation of intercultural communication in the sphere of pre-school, school and university education.

The content of education should provide general and professional culture of the society adequate to the international level, formation of students' picture of the world adequate to the educational program level, the integration of the individual into the national and world culture. The subject of "foreign language" not only introduces the culture of the target language, but by comparison emphasizes the features of their national culture, familiarize with human values. In other words, it contributes to teaching of pupils in the context of "dialogue of cultures".

In this paper, the term "culture of the country of the target language" refers to a set of knowledge and experience, enabling students to be appropriate members of intercultural communication. 
Bringing culture materials promotes the awakening of cognitive motivation, that is, the students not only master the program material, but also get acquainted with the unknown facts of culture, which certainly causes them concern. Therefore, the learning process taking into account the interests of the pupils is particularly effective.

Modern purpose of learning a foreign language and culture can be formulated as a preparation for real intercultural communication. Some authors interpret intercultural communication as an adequate understanding of communication participants belonging to different national cultures. Exactly, this statement of teaching meets the needs, requirements for foreign languages at the present stage of development of society. Currently, the question of the admission of a resident of the XXI century to the world culture, of the bringing his level of education to the European standard, of the ability to speak at least two foreign languages is put forward. And it is not a coincidence, since, with the strengthening of interaction of societies and interpenetration of cultures, we clearly formulate the process of mass introduction of foreign language teaching, in which the solid foundations can and should be laid down, which are needed by a person to participate in direct and indirect dialogue of cultures. To do this, in turn, it is necessary to gradually get acquainted with the history and contemporary life of the country whose language is studied, its traditions and culture through the target language.

According to N.D. Galskova in the content of foreign language teaching we must include:

- spheres of communication activities, themes and situations, speech acts and speech material, taking into account the professional orientation of students;

- language material (phonetic, lexical, grammatical, spelling), the rules of its design and skills to operate it;

- a set of special (verbal) skills that characterize the level of practical mastery of a foreign language as a means of communication, including intercultural situations;

- a system of knowledge of national and cultural characteristics and realities of the country of the target language Gal'skova N.D., 2000, 92).

As many psychologists agree it is in the teen years when the most intensive development of a man's abilities and talents occur. In spite of the fact that it is rather short time period in the development of the personality, during the school time a person learns more than throughout the whole life. The 'program' of schooling is really huge: development of attention, acquiring the speech, establishment of thinking, development of imagination, perception, forming of the relationships with other people - all these processes happen at adolescence.

Nowadays the thesis about embodying culture knowledge into the programme of teaching foreign languages is supported by most methodologists. Culture knowledge is the basic richness of teaching the language. It is a generally known fact that the primary stage of education gives a start and influences a lot the following period of language learning. So it is important to form a solid foundation of all components of the content of language teaching including socio-cultural component. Socio-cultural approach causes a new approach to the whole content of teaching where every component should be enriched by the culture knowledge including the native culture and culture of the target language to assist in the dialogue of cultures.

Within the global integration of the world countries it has become significant to be culturally aware in order to understand the social and cultural background of representatives of different countries. On the other hand, there are reasonable perspectives for a country to collaborate with foreign countries, which facilitate the development of the dialogue of countries and interaction. Better understanding of sociocultural peculiarities of a partner-country enables efficient cooperation in any sphere of life.

Younger generation is very flexible about establishing contacts with foreigners-teenagers, communicating with native speakers on "urgent" topics. After graduating from lower and higher secondary schools they have an excellent opportunity to continue their education abroad as well as find there a job. Linguistic competence combined with the sociocultural one makes it easier to orient oneself in a vast foreign expanse. It is expedient to develop socio-cultural competence at the age of 12-18 when adolescents are aware of the necessity to follow definite patterns of communicative behaviour according to both social and cultural features of their interlocutors' country, besides this awareness lets the youth feel at ease while dealing with foreigners within an alien environment.

A student or any other person studying a foreign language widens his or her mind and transforms it in a way by learning a foreign language. A competence-oriented approach to education has recently gained its popularity; it means that when teaching students a discipline, there should be a specified complex of specific knowledge and skills (competences) to be obtained and mastered by the end of study which are necessary 
in their future profession or everyday life. These competences are usually designated in the State educational standards in accordance with students' grade, age, physiological peculiarities and degree of competence need.

The importance of socio-cultural competence starts growing in secondary and high schools since adolescents become especially involved and concerned about the world's culture; they have mastered A2 and B1 levels of language proficiency by that time in the field of different foreign languages (English, German, French, or some other languages) and a native one. It is essential that they should adequately interpret the "non-likeness" and / or overlapping of different cultures (in definite cases even intrusion into a native one) and have a tolerant attitude to this phenomenon. Otherwise they may develop a wrong idea about the modern world culture alongside with misunderstanding of the native tongue's role against the world cultural background.

High school students occupy an intermediate position on their way to adult life with their own stereotypes, feelings and perceptions. Undue interference into the process aimed at absorbing knowledge has grave consequences in further education or professional activity. They must be ready to improve their basic communicative and socio-cultural skills in high school.

If we consider the concept of "competence" in terms of the educational process, we can say that competence is primarily the result of training. Through the study of educational material the student acquires a particular competence - specific knowledge, skills - and gains experience (professional quality) and thus demonstrates perseverance, self-reliance and responsibility (personal qualities). In addition, competence in the educational process is the result of integrated learning (the integration of theory and practice, the integration of teaching methods and educational technologies, the integration of academic disciplines).

Competence is characterized by the possibility (the ability, willingness) to apply knowledge and skills in real life, showing the best personal qualities.

Next, consider the ways and forms of cross-cultural interaction.

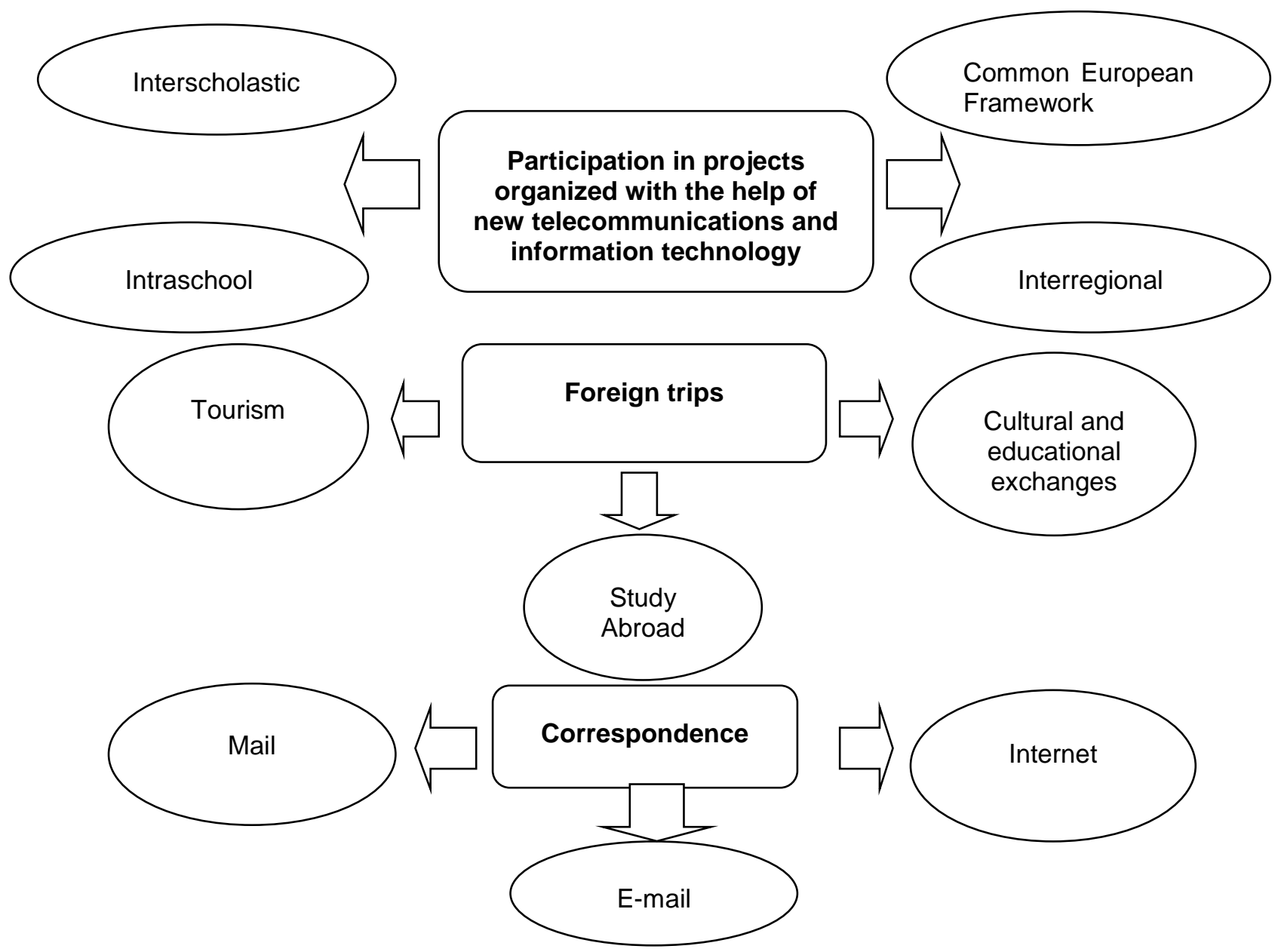

.Fig. 2. Types and methods of intercultural communication. 
From the above we can say that the possible types and methods of intercultural communication should become an integral component of the educational process.

Formation of intercultural competence should be seen in connection with the development of the student's personality, his ability and willingness to participate in the dialogue of cultures on the basis of the principles of cooperation, mutual respect and tolerance for cultural differences and overcoming cultural barriers, particularly for modern foreign language teaching. That person Dialogism it is an important factor (ID) of and as a result makes it capable of participating in the dialogue of cultures.

Thus, the process of formation of the intercultural competence of the student's vocation to expand its overall outlook and overall competence. The development of the individual student, is in the comparison of at least two linguocultures, carried out on the basis of their own world view and understanding of the world and involves the perception and reflection of their own values and social relationships.

Socio-cultural competence is a complex phenomenon. It includes the following components:

- Linguistic-cultural - knowledge of lexical items with the socio-cultural semantics (e.g., greeting, forms of address, and farewell, in oral and written speech);

- Socio-linguistic - knowledge of the language features of social classes, different generations, genders, social groups;

- Cultural component - knowledge of cultural peculiarities of English-speaking countries, their habits, traditions, standards of behaviour, etiquette and the ability to understand and use them appropriately in the communication process, while remaining a carrier of another culture.

G.A.Vorobjev notes "socio-cultural competence is a complex phenomenon and includes a set of components belonging to different categories" (Vorobjev G.A.,2003, pp.30-35).

According to R.P. Milrud, "socio-cultural competence refers to the activity-component of communicative competence" (Milrud V.P., 2004, pp.31-35).

V.V. Safonova believes that "didactic description of the objectives of socio-cultural education by means of a foreign language is to be done in terms of socio-cultural competence" (Safonova V.V., 2001, pp.17-22).

We understand socio-cultural competence as the possession of and the ability to apply a set of multicultural knowledge, skills and qualities in the process of intercultural communication in the specific conditions of life and tolerance towards people of other nationalities.

The formation of socio-cultural competence is carried out in three stages; each stage has its own challenges due to its objectives.

The first stage is "motivational", i.e. providing psychological readiness to communicate with all learners. M.I. Dyachenko and L.A. Kandybovich and other scientists highlighted the problem of readiness at different times and from different positions in their research. Thus, readiness is a particular mental state that allows you to perceive a certain situation or to act (Dyachenko M.I., Kandybovich L.A., 1976, p.86).

The objective of this stage is to interest students in gaining knowledge about different peoples and their cultures, to show how diverse both the world is and the people living in this world, to achieve a positive attitude towards learning about other cultures and to awaken in them the desire to interact with other cultures. P.P.Stepanov states that the main goal of a teacher is not only to give information on different cultures, but to change trainees' treatment of other cultures (Stepanov P.P., 2001, pp.152-156). At this stage, the native language is used along with English because the information given in the native language quickly comes to mind. Watching feature films and documentaries describing the way of life, traditions and customs of different nationalities and discussing them appears to be effective. Discussion takes a specific place in the sphere of dialogic communication. The main objective of the discussion is the development of communicative culture in the search for the truth. Awareness of and understanding the problems and contradictions, identification of available information, revision of knowledge, development of skills to argue and justify the point of view, inclusion of knowledge in a new context are the main substantial objectives of discussion.

N.A. Astashova asserts that a skilfully organised discussion is the most important form of the methodical development of tolerance. Within the scope of work with trainees by means of directed reflection common cultural values are converted to values of personal character where tolerant relations occupy their rightful place (Astashova N.A., 2003, pp.80-85).

E.M. Adzhieva believes that the moral value of the idea of a dialogue is in the objective perception of the 
diversity of the surrounding people, nations and cultures (Adzhieva E.M., 2003, p.92).

In the spotlight is the fact that sensible people all around the world, regardless of their nationality or religion, show tolerance of and respect for each other and appreciate the cultural heritage of the community. The core values of all peoples are the same. Discussing the movies seen helps students to penetrate the essence of the question, and gives them a chance to ask questions and express their opinion. This work makes it possible to achieve the goal - to form a new quality of a person - a willingness to cooperate.

The second stage of the formation of socio-cultural competence is "informative". The main objectives of this phase are the collecting and processing of learning material, which is the content of training. The law of the Respublic of Kazakhstan "On Education" states that the content of education should promote understanding and cooperation between peoples and nations, irrespective of race, nationality, ethnicity, religion or social origin and take into account a variety of philosophical approaches.

We consider the content of training as a constantly changing and evolving category connected with the process of learning. An interrelation of the activities of teaching (the activity of the teacher) and learning (student activities) is addressed in the material, or in other words, in the content of the subject. The content of education is not only the subject of what you can hear or see in the lesson that is explicitly expressed or clearly represented by a teacher or a student, but also what they think, feel and experience, as well as the mental processes that occur in their "heads" when one opens up and the other develops the world of a different culture. We are not talking about the formation by a trainee of a new consciousness, totally identical to the host consciousness of the target language.

The task is to enrich the student's consciousness through initiation into the image of linguistic consciousness of his peers abroad - carriers of other conceptual systems of the world. The perception of any material has a bright personality colour. A preliminary analysis of the materials is worked up by using one's own experience and available knowledge. Students prepare a monologue speech on the issue, and make up questions. Thus it is not only familiarising the student with living modern English but also enriching the vocabulary, broadening the outlook, "immersing" in a foreign cultural environment and increasing the motivation for learning a foreign language.

Training material, in our opinion, must meet the following criteria: cross-cultural content, modernity, actuality and credibility.

The next step is to organise cooperation on the basis of subject-oriented, motivated communication activities between students themselves and with the teacher.

All the complexity of studying a foreign language from the point of view of psychology is that the attention of the trainee is distributed simultaneously to multiple objects: the definition of the content of statements, selection and fixation of linguistic resources, establishing and keeping in mind a logical sequence of statements, its implementation in the external plan (speaking). During training, the teacher should help the student to organize his/her thoughts, clarify the solution to the problem of communication, find ways for its implementation and create the conditions of natural communication in the target language if that language is not an end in itself but a means of communication. Material for communication should not require specialised knowledge, but must arouse interest, inducing the expression of one's own opinion and assessment.

Pair or group work creates a situation close to the real conditions of foreign language communication in the classroom. An effective form of group work is gaming technology. The game develops creative thinking, fosters a culture of communication and allows you to organise spontaneous communication in class when the learning situation becomes natural. V.M. Ustinenko, considering the game as a cultural phenomenon, believes that "the game is one of the ways of learning the world, and self-affirmation of an individual when a person takes on the role (not real but imaginary) and puts himself into a conditional situation" (Ustinenko V.M., 1980, p.70). A variety of aspects of the game are highlighted in the study of domestic and foreign educators and psychologists. The game is seen as a means of knowledge and self-knowledge. The right selection of situational roles and themes for the games are of great importance. An unknown subject cannot be the subject of discussion even in their native language, but especially in the foreign language.

The project-method, which has been used by the teachers, suggests an independent cognitive activity of students on the given topic or issue. What is important about this method is that the trainee focuses his/her attention not on the English language but the problem researched. In project work language is used for its essential purpose of exchanging information; it becomes more of a means than an objective. Students learn not only new words but also learn new things and new ways of doing things. The original idea of this method is to involve students in "learning by doing" activities, which allows them to choose what they want to study and create an end-product based on their activities. The main idea of students' presentations is to reflect the 
vibrant culture of the people living on different continents.

We would like to mention that the methods used by the teachers in the process of learning activities are based on the conscious-comparative approach. This is based on the principle of awareness of linguistic phenomena in the period of learning and using, and on the principle of a comparative study of a foreign language with a native language. The stage of comprehension, comparing, analysing and correcting is the most important in the work, as this is exactly where the intellectual growth and development of personality, the disclosure of students' personal potentials and awakening of their interest in knowledge of and familiarity with the foreign culture happens, i.e. the formation of socio-cultural competence.

The final stage of the work is the formation of the concept of "socio-cultural competence" together with the students, defining the means of its manifestations in contemporary conditions and its practical consequences. The students make up some possible strategies to oppose prejudice and preconception. Filling out a questionnaire with the list of countries and nationalities is followed by discussion and determining the slogan for life. Here are some of them: "Do you want to change the world for the better? Start with yourself"; "Treat people the way you would like them to treat you"; "Be friendly and you will see how the world around you has changed"; "Man is born for happiness", and others.

According to L.V. Mardakhaev the indices signifying the development of socio-cultural competence by high school students are (Mardakhaev L.V., 2005, pp.121-122):

- their comprehension of the notion "culture" as a unit of culture products (literature, folklore, works of art, music, artifacts), ideas beliefs, customs, taboos, codes, institutions, tools, techniques, rituals, ceremonies, and symbols.

- their realization that person's behaviour is greatly conditioned by his or her cultural characteristic;

- their understanding that all social diversities (age, sex, social class, place of residence) influence person's speech;

- their tolerant attitude towards other cultures;

- their understanding of the conventional character of communicative and non-communicative behaviour of people who represent different countries in different situations;

- their adoption of their own cultural behaviour;

- developed skills of its analysis;

- developed abilities to identify cultural connotations and decode them;

- developed skills to identify, distinguish and use effectively cultural codes for the achievement of the main communicative aim;

- developed skills to identify cultural peculiarities reflected in speech;

- mastered methods aimed at analyzing diverse cultural phenomenon as well as developed critical thinking;

- developed skills to define the way their own sociocultural characteristic influences their behaviour;

- developed skills to correct their behaviour according to a situation.

Visiting foreign countries, participating in educational and cultural events dedicated to foreign countries, meeting native speakers, conducting joint projects with foreign teenagers, staying in summer and winter camps with foreign teenagers facilitate the development of the students' socio-cultural competence.

To make a conclusion, the mentioned socio-cultural competence within high school curriculum constitutes general communicative competence and functions as the basis of cultural identification which presupposes successful intercultural communication in future due to properly developed specific sociocultural skills. These competence is extremely important in the sphere of foreign and native language study; it is mastered by students are in parallel with oral topics and corresponding assignments in high school. Higher school helps to develop it according to professional specifications. It is considered to be substantial to devote further research to the problems of criteria elaboration aimed at evaluating levels of high school students' sociocultural competence development. 


\section{REFERENCE LIST}

Davidson D., Mitrofanova O.D. (1990). Russian language and literature in dialogue nations of the world: the problem of functioning and teaching. Functioning of the Russian language: methodical aspect: plenary report, p.3.

Khaleeva I.I. (1989). Basic theory of learning foreign speech understanding (training interpreter). Moscow Journal of Higher School, p. 238.

Ushakova T.N. (1986). Speech as a cognitive process and as a means of communication. Cognitive Psychology, p.137.

Baryshnikov N.V. (2000). Fundamentals of professional intercultural communication. Moscow. pp.5-13.

Hall E. (1959). The Silent Language. The mute language, p.169.

Frake C. (1981). Plying Frames Can Be Dangerous: Some Reflections on Methodology in Cognitive Anthropology. Language, Culture and Cognition / ed. by R. Casson. NY: Macmillan, pp.138-150.

Weaver G.R. (1993). Understanding and Coping with Cross-Cultural Adjustment Stress // Education for the Intercultural Experience / ed. by R.M. Paige. U.S.A .: Intercultural Press, pp.137-167.

Kosherbaeva G.N. (2003). Intercultural dialogue in the process of extracurricular activities. Scientific application of the international scientific-pedagogical magazine "Higher School of Kazakhstan", abstract №2, pp.80-84.

Temirgazina Z.K. (2003). Intercultural and interethnic communication: to the problem. Problems of intercultural communication in the modern educational space. Proceedings of the international scientific-practical conference. - Tobolsk, pp.188-190.

Dzhanseitova S.S. (2002). Art and shaped the concept of the concept of "dialogue of cultures". Bulletin of KNU. A series of philological №54 (3), pp.165-170.

Gal'skova N.D. (2000). Contemporary methods of teaching foreign languages. Teachers book, Arcti-Glossa. p.165.

Vorobjev G.A. (2003). The development of socio-cultural competence. Foreign Languages in School. p.98.

Milrud, V.P. (2004). Competence in language learning. Foreign Languages in School. p.176.

Safonova V.V. (2001). Cultural studies in the modern language education. Foreign Languages in School. p.220.

Dyachenko M.I. \& Kandybovich L.A. (1976). Psychological problems of readiness for activities. Publishing House of the Belarusian University. p.114.

Stepanov P.P. (2001). A tolerant person: How to bring him up. Public Education. p.208.

Astashova N.A. (2003). The problem of formation of tolerance in the system of educational institutions. Tolerant Consciousness and Formation of Tolerant Relations (Theory and Practice). p.163.

Adzhieva E.M. (2003). Ethnopedagogical and ethnopsycological conditions of fostering of tolerance. Tolerant Consciousness and Formation of Tolerant Relations (Theory and Practice). p.182.

Ustinenko V.M. (1980). The place and role of the phenomenon of the game in the culture. Philosophy. p.136.

Mardakhaev L.V. (2005). Social pedagogics. Book. Moscow. Gardariki. p.269. 